\title{
Testicular Cancer Awareness among Men Residing in the Maltese Islands
}

\author{
Vincent Marmarà \\ University of Malta Faculty of Economics Management and Accountancy \\ Reginald Aquilina \\ Ministry for Health Malta \\ Elyse Formosa \\ Ministry for Health \\ Gill Hubbard \\ University of Highlands and Islands \\ Danika Marmarà ( $\nabla$ attard.danika@gmail.com ) \\ University of Stirling Faculty of Health Sciences https://orcid.org/0000-0001-6619-8759
}

\section{Research article}

Keywords: Testicular cancer, Testicular self-examination, Awareness, Knowledge, Public campaigns, Interventions

Posted Date: November 19th, 2020

DOI: https://doi.org/10.21203/rs.3.rs-59692/v1

License: (c) (i) This work is licensed under a Creative Commons Attribution 4.0 International License. Read Full License 


\section{Abstract}

\section{Background}

Testicular cancer (TC) accounts for around one percent of all cancers in men. Early detection is of utmost importance for recovery and survivorship. Testicular self-examination (TSE) has been shown to be effective in preventing late-stage TC diagnosis. However, there is a lack of knowledge and awareness of both TC and TSE in men. Increasing such awareness may contribute towards earlier TC detection and positive outcomes. This study aims to assess the level of knowledge of a representative sample of the Maltese male population on TC and TSE. It also explores men's willingness to learn about and perform TSE as well as their suggested approaches for TC and TSE information provision.

\section{Methods}

A telephone interview approach was chosen using an interview schedule, developed based on established literature. Data were collected from a random sample of 400 male respondents aged 16 years or over and stratified according to all ages and districts of Malta.

\section{Results}

The findings of this study indicate that Maltese males lack knowledge on TC and how to carry out TSE. Only $36.9 \%$ respondents had knowledge on how to perform TSE and 33.9\% had practised TSE at least once in their lives. Higher educated, higher income and younger respondents scored better. This study also found that only $9.6 \%$ of respondents were informed by a doctor about TSE, indicating a notable gap in information provision. However, $87.3 \%$ of respondents knew that TC can be treated if identified at an early stage and $90.2 \%$ of males were ready to perform TSE on a regular basis if informed how to perform it. The majority of participants believed that increasing awareness of TC and TSE is important.

\section{Conclusions}

Knowledge on TC and TSE is low in Malta. Health education campaigns are needed to inform the general population about the risks of TC and how to perform TSE. Such campaigns could improve early detection and hence a decrease in the number of advanced TC cases. The findings of this study are being used by the Ministry for Health and the Marigold Foundation to launch campaigns to raise awareness about TC and TSE.

\section{Background}

Testicular cancer (TC) is the most common cancer to affect young males with disease incidence peaking between 15 and 40 years of age [1, 2]. TC accounts for around $1 \%-1.5 \%$ of all male cancers around the world [3-5]. Incidence rates of TC are rising in most Caucasian and European ancestry populations within the developed world, where it is the most commonly diagnosed malignancy in young men [6-8]. About 310 new cases of TC per 100,000 males/per year are diagnosed in Western societies with potential growth of $25 \%$ by 2025 in Europe [5]. TC incidence rate is also twice as high in higher socioeconomic groups compared with lower socioeconomic groups [9]. Le Cornet et al. [5] project that the vast majority of European countries will see an increasing burden over the next two decades. They estimate there will be 23,000 new cases of TC annually in Europe by 2025, a rise of $24 \%$ from 2005. Northern Europe is the highest TC incidence area, with the highest rates observed in northern European countries including Norway and Denmark [10]. Presently, the average incidence of TC in Malta over the past 5 years was of about 18 testicular cancer cases per year [11]. The highest incidence was for 25 to 49 year old Maltese males $(0.63 \%)$ of the 90 total cases for the five years. As in other countries, the incidence of TC is increasing in Malta with an increase of about $0.5 \%$ when comparing incidence of 2014 with the average incidence for years 2015 to 2018.

Treatment of TC, which often includes orchiectomy, radiotherapy and chemotherapy, has become extremely successful $[3,12]$ and TC is now curable in many cases especially if detected at an early stage. Males who find a lump in its early stages frequently have a 5-year net survival rate of between $95-97 \%$ [13-15] and a 10-year survival rate as high as $98.2 \%$ [16]. However, delay in TC diagnosis is a major challenge for successful treatment and those presenting at a later stage of the disease have poorer prognosis [17]. It has been reported that men usually delay seeking treatment for TC for an average of 16 weeks after symptoms develop [18]. Studies suggest that reasons for delay in seeking help among men include lack of knowledge of TC symptoms (e.g. testicular lump, scrotal swelling), lack of perceived symptom severity, lack of perceived susceptibility to serious illness and fear of cancer and death [17, 19-24]. It is therefore important to examine what might encourage men to adopt health seeking behaviours.

Regular testicular self-examination (TSE) has been recommended as a means of early detection of TC [25]. It can be used by at-risk males to regularly and systematically examine their testicles and ensure early detection of TC. TSE is a simple technique that is easy to teach and learn through health interventions [26-32]. However, males in the general population have poor awareness of TSE and how it is done $[23,29,33,34]$ and do not regularly perform self-examinations [23]. In addition to lack of knowledge of TSE, reasons for not performing TSE may include lack 
of understanding of the severity of TC, lack of belief about the effectiveness of TSE [35] or perceived lack of time to perform the examination $[37,38]$. Increasing men's awareness and knowledge of both TC and TSE may contribute towards increased rates of TSE, earlier TC detection and better survival rates.

This study aims to assess the level of knowledge of a representative sample of the Maltese male population on TC and TSE in an effort to provide insight into the need for public education on TC and TSE. It also explores their willingness to learn about and perform TSE as well as men's suggested approaches for TC and TSE information provision. In addition, the study explored the association between various demographic factors and knowledge and practice of TSE by testing the following hypotheses:

Hypothesis 1: There is an association between level of education and knowledge of TSE.

Hypothesis 2: There is an association between place of residence and knowledge on TSE.

Hypothesis 3: There is an association between knowledge of TSE and practice of TSE.

Hypothesis 4: There is an association between age and knowledge of TSE.

Hypothesis 5: There is an association between knowledge of TSE and prior history of TC in the family.

Hypothesis 6: There is an association between practice of TSE and prior history of TC in the family.

\section{Methods}

\section{Study design}

The project adopted a cross-sectional design where a survey was administered by telephone to potential participants. A cross-sectional approach was deemed suitable because wide variety of ages can be studied in a short period of time [39]. A telephone survey was chosen instead of postal questionnaires or face-to-face questionnaires as the anonymity might increase response rates and data can be collected more rapidly and cost-effectively [40]. This was deemed important as it is known that men tend to not want to participate in health studies [41]. The advantages of a telephone survey over other survey modes is that it provides the opportunity for "continuous quality control over the entire data collection process" [40].

\section{Setting}

The study was carried out in Malta between August 2019 and September 2019. Data collection was carried out at Sir Anthony Mamo Oncology Centre at the Offices of the Cancer Care Pathways Directorate.

\section{Participants}

A survey was conducted among 400 men residing in the Maltese Islands. This survey was directed only towards men who were 16 years of age and older. Hence, the target population was the finite population of men residing in the Maltese islands. The female Maltese population was not included in this survey. One way to ensure that the questionnaire is effective is by considering and sticking to the purpose of the research, that is information gathered from male respondents. On contacting the participant, the researcher conducting the phone calls requested the participation of a male respondent.

\section{Data collection}

Participants were recruited by telephone, by three trained research assistants (EF, RF, AAF). Potential participants were provided with information about the study, including aims, time commitment and confidentiality. For those participants who affirmed they were willing to take part, verbal informed consent was obtained where the researcher used a paper consent and recorded whether the participant gave consent [42]. Verbal consent is common practice when conducting survey interviews or interventions by telephone [42] and was chosen because it facilitates comprehension of study objectives and questionnaire items, and reduces the unnecessary burden entailed in a written consent form [43].

Data entry was carried out through the use of computer-assisted technology through an online study tool (the SurveyMonkey program).

\section{Variables}

Modifying factors include socio-demographic and health status variables, and structural variables such as knowledge of testicular examination frequency and knowledge of the disease.

\section{Bias}


In order to reduce bias, a random selection of contact numbers was computer generated in an effort to address potential sources of bias.

\section{Study size and sampling technique}

The level of confidence was chosen and hence a sample of 400 men residing in the Maltese islands was chosen from this population. In order to ensure that the study sample was nationally representative of the Maltese male population and to decrease the margin of error in the estimation, men were selected by a stratified random sampling technique, employed by strata i.e. district (geographical distribution) and age.

The target population was estimated to be 214,000 men between the ages of 16 and over [44]. A sample size of 400 men was determined using a $95 \%$ confidence level and a $5 \%$ confidence interval. Forty-five men refused to participate in this study (due to two reported personal reasons, i.e. lack of time due to work and family; fearful to speak about the topic under investigation). All 45 men were free to provide their own reason for non-participation. Content analysis of open-ended comments on reasons for refusal was employed, and later categorised and classified as being one of the above two reasons. Reason for refusal by male respondents was similar to other studies which focused on awareness of TC and TSE [32, 37, 45-47]. Due to the men's refused participation, 445 men were eventually contacted in order to reach the necessary quota for each strata (with $90 \%$ response rate). All replacements were carried out in a way so as not to lose any of the sample representativeness of the population. Hence, replacements were selected with the same demographics of the non-respondent.

\section{Measures}

The questionnaire was developed using international journals that focused on similar research [32, 37, 45-47]. These scales were used after securing written permission from the authors and were translated and adapted into the Maltese language and tested for validity in a pilot study involving 15 Maltese men. The interview guide was developed for this study [Additional File 1].

The 18-item questionnaire was composed of two sections. The first section focused on information concerning the knowledge and awareness on TC and TSE whilst the second section focused on demographic information such as age, location and social status. The latter was used to create relationships between the questions asked in the first section. The first 3 items were asked to check if the participant had knowledge on how to perform the TSE. Another 3 questions were asked to test the participants' knowledge on the frequency of the TSE, the age group with the highest incidences and the TC symptoms. Further to this, the respondents were asked 2 more questions on whether they thought that TC could be cured and if they are willing to perform TSE to detect TC earlier. In addition, they were also asked if they think that giving information on TC to the public is important and the best interventions to do so. Another 2 items concerned personal information where the respondent was asked whether they or their family had any prior problems related to testicles. Finally, the participant was asked 6 items related to age, residing district, education, employment, marital status and family income. Moreover, open-ended questions were asked when it was believed to be important that men could provide further detail, for example, when the participant was asked what the main reasons for not performing TSE were.

\section{Statistical methods}

Data were downloaded from the online survey platform by the primary investigators (VM, DM). Minor formatting adjustments were made to the raw aggregate data in Microsoft Excel, and then the data were exported into the Statistical Package for the Social Sciences (SPSS). This method of handling data significantly decreased human error in the data entry process. This procedure of data storage and handling was secure, ensuring confidentiality of information provided by participants.

Summary statistics were calculated using statistical software package - SPSS ${ }^{\circ}$ version 21.0 under direct instruction and guidance of an expert statistician (VM). More in-depth analysis was also carried out such as testing hypothesis, correlation and comparison.

The reason for dividing the participants into several age groups was so that there would be a wider knowledge of how much different age groups are aware and have knowledge on TC and TSE. This was also used to distinguish between age groups and places of residence.

Descriptive and inferential statistics, such as percentages, frequencies, means, standard deviations and confidence intervals, were used to present the basic statistics in relation to the demographics, knowledge, beliefs and attitude variables. Chi-square tests were performed to determine significant associations between one categorical variable and another categorical variable to investigate the associations of health beliefs, attitudes, knowledge and socio-demographic factors with testicular self-examination.

\section{Results}

\section{Participants}

The survey was completed by 400 males. Most of the participants came from the Northern Harbour with a value of $28 \%$. The age group with the most respondents in our survey was that of the ages 66 and over with a value of $20.7 \%$, whilst the age group with the lowest respondents 
in our survey was that of the ages between 16 and 25 with a total value of $10.7 \%$.

Most participants reported not having problems related to their testicles (93.62\%) and $87.59 \%$ reported no family history of TC.

\section{Explanatory Data Analysis Knowledge of TC}

Respondents were asked about their knowledge of possible signs and symptoms of TC. The study revealed that $72 \%$ answered correctly when asked whether a difference between the testicles or the presence of a lump or swelling is a symptom of TC. On the other hand, $6.6 \%$ answered incorrectly that coughing bouts at night is a symptom of TC. Only $20.9 \%$ thought that aching in the lower back can be a related symptom of TC (when in fact it could be), whilst only $27.3 \%$ thought that build-up of fluid or a feeling of heaviness or sensitivity in the scrotum is a symptom of TC (when in fact it is). Moreover, $40 \%$ incorrectly thought that pain on passing urine is another symptom of this cancer.

Participants were also asked about their perception of TC curability. The majority (87.3\%) believed that if TC is treated at an early stage, it can be cured. However, approximately $10 \%$ were unsure and $2.3 \%$ thought TC cannot be cured. The majority of participants (90.21\%) were ready to perform TSE on a regular basis to help detect early signs of TC.

Knowledge of the relationship between age and incidence of testicular cancer was variable. Only $16.6 \%$ of the respondents answered correctly that the age group with the highest tendency of TC is the age group between 15 and 44 years. Approximately half of the study participants $(49.8 \%)$ incorrectly assumed that there was no particular age when incidence of TC is higher.

\section{Knowledge And Practice Of TSE}

The results show that only $36.9 \%$ of men in the current study had knowledge on how to perform a TSE and only $9.63 \%$ have been shown by a doctor how to perform the examination. When asked, how often they think TSE should be performed, less than half of the sample (40.9\%) correctly answered that a TSE should be done once a month while $38.9 \%$ thought that practicing a self-examination once a year was sufficient. The remainder believed that TSE should be performed weekly $(11.1 \%)$ or daily $(9.1 \%)$.

More than half of the participants (66.1\%) had never practiced TSE whilst only 33.9\% had practiced TSE at least once in their lives. The main reason why most males never practised TSE was due to not knowing how to do a self-examination (86.2\%). This was followed by no desire to do practise TSE (12.1\%), fear of detecting something wrong (6.6\%), fear the procedure could be painful or damaging (2.1\%), feelings of embarrassment to perform the self-examination (2.1\%) and perception that their risk of TC is small (1.7\%).

The study also explored whether knowledge of TSE varies according to participants' age, education, employment status and income level.

The results showed that younger people were more aware of how to do a TSE, compared to older people (Fig. 1).

Individuals with a higher level of education were also more aware of how to do a TSE, when compared to individuals with a lower level of education (Fig. 2).

Employed people and students were more aware of how to do a TSE, compared to unemployed individuals and pensioners (Fig. 3).

Finally, individuals with a higher income were more aware of how to do a TSE, compared to individuals with a lower income (Fig. 4).

\section{Perceived views on the need for a public health information campaign}

Findings also revealed that $97.7 \%$ of the respondents deemed the need for public information on TC as important. A media campaign was suggested by $32.5 \%$ of respondents, whilst $12.7 \%$ claimed that a radio campaign would be an effective intervention. A social media campaign was proposed by $27.9 \%$. Printed information in pamphlets and in newspapers/magazines was believed to be an effective way to raise awareness of TC (17.2\% and $9.8 \%$ respectively).

\section{Hypothesis Testing}

Hypothesis 1: There is an association between level of education and knowledge of TSE. 
A chi-square showed that the association between level of education and knowledge of TSE was significant $x^{2}(6, \mathrm{n}=436)=46.259, \mathrm{p}<0.001$. This shows that knowledge of TSE is positively associated with higher level of education, therefore the null hypothesis was rejected.

\section{Hypothesis 2: There is an association between place of residence and knowledge on TSE}

A chi-square showed that the association between place of residence and knowledge of TSE was not significant $x^{2}(5, \mathrm{n}=439)=3.312, \mathrm{p}=$ 0.652. There is not enough evidence to reject the null hypothesis, meaning that knowledge on TSE is not associated to the place of residence of the respondent.

\section{Hypothesis 3: There is an association between knowledge of TSE and practice of TSE}

A chi-square showed that the association between knowledge of TSE and practice of TSE was significant $x^{2}(5, \mathrm{n}=439)=345.70, \mathrm{p}<0.001$. This shows that higher level of TSE knowledge is associated with a higher chance of performing TSE, hence the null hypothesis was rejected.

Table 1 shows the results from a chi-square test for the different TSE behaviours. The chi-square test showed only one significant relationship and this is between not knowing how to perform a TSE and knowledge of TSE. The remainder of measured behaviors were not associated with knowledge of TSE.

Table 1

Chi-square results for TSE behaviours

\begin{tabular}{|llllll|}
\hline \multicolumn{7}{|c|}{ Testicular Self-Examination Behaviour } & & \\
\hline & $\begin{array}{l}\text { Fearful of } \\
\text { detecting } \\
\text { something }\end{array}$ & $\begin{array}{l}\text { Embarrassing to } \\
\text { do the self- } \\
\text { examination }\end{array}$ & $\begin{array}{l}\text { The risk of } \\
\text { testicular } \\
\text { cancer is small }\end{array}$ & $\begin{array}{l}\text { Cannot be bothered } \\
\text { to do the self- } \\
\text { examination }\end{array}$ & $\begin{array}{l}\text { Fear that the } \\
\text { procedure is painful } \\
\text { or damaging }\end{array}$ \\
$\begin{array}{l}\text { Pearson } \\
\text { Chi- } \\
\text { Square }\end{array}$ & 3.802 & 0.448 & 0.621 & 2.044 & 3.558 \\
$\begin{array}{l}\text { Test } \\
\text { P-value }\end{array}$ & 0.051 & 0.503 & 0.431 & 0.153 & 0.059 \\
\hline
\end{tabular}

Hypothesis 4: There is an association between age and knowledge of TSE

A chi-square showed that the association between age and knowledge of TSE was significant $x^{2}(5, \mathrm{n}=439)=23.837, \mathrm{p}<0.001$. This shows that knowledge of TSE is associated with the age of the respondent, therefore the null hypothesis was rejected.

Hypothesis 5: There is an association between knowledge of TSE and prior history of TC in the family.

A chi-square showed that the association between knowledge of TSE and prior history of TC in the family was significant $x^{2}(6, n=435)=$ $6.518, p=0.038$. This shows that not having prior history of TC in the family is associated with higher lack of knowledge. Therefore, the null hypothesis was rejected.

Hypothesis 6: There is an association between practice of TSE and prior history of TC in the family.

A chi-square showed that the association between practice of TSE and prior history of TC in the family was significant $x^{2}(6, \mathrm{n}=435)=8.435$, $p=0.015$. This shows that not having prior history of TC in the family is associated with higher lack of TSE practices. Therefore, the null hypothesis was rejected.

\section{Discussion}

This study assessed the level of knowledge of a representative sample of the Maltese male population on TC and TSE, and the association between various demographic factors and knowledge and practice of TSE. The study also explored men's willingness to learn about and perform TSE as well as their suggestions for how such information can be provided.

The majority of participants were aware that swelling or a lump is a symptom of TC but knowledge of other TC symptoms was variable. In addition, knowledge of the relationship between age and incidence of TC was variable. Most of the participants believed that TC can be cured.

When asked about TSE, most participants were ready to perform it on a regular basis, although less than half knew that TSE should be performed once a month. More than half of the respondents had never performed TSE and the main reason for this was due to lack of 
knowledge about how to do a self-examination. This is not surprising as a very small number of participants (approx. 10\%) have been shown by a doctor how to perform TSE.

The results also show that people in employment, students and those with higher income have better knowledge of TSE. There were significant associations between knowledge of TSE higher level of education, younger age and history of TC in the family. There were also significant associations between practice of TSE and knowledge of TSE and history of TC in the family.

Finally, almost all of the respondents deemed the need for public information on TC as important, with the majority of these suggesting the use of a media or social media campaign.

The variable knowledge of TC symptoms in the current sample is not surprising, as lack of knowledge of TC symptoms among men in the general population has been highlighted before [23, 32,37]. However, the fact that most participants correctly identified that difference between testicles like presence of lump or swelling in one testicle as a sign of potential TC shows that men are aware of an important TC symptom and suggests the need for more education about other symptoms of TC. Moore and Topping [24] reported similar results with 74\% of participants correctly indicating that lumps were associated with TC. Similarly to previous research, the men in this study correctly answered that if TC is treated at an early stage it can be cured [48].

This study found an association between knowledge of TSE and actual performance of TSE, which is consistent with previous research [22, 37]. The majority of men in this study were willing to perform TSE on a regular basis but more than half had never done it before and reported lack of knowledge on how to do TSE. These results are consistent with previous literature, which shows low knowledge of TSE amongst males $[23,35,37,48-52]$. The fact that approximately $10 \%$ of the men in the current study were shown by a doctor how to perform TSE indicates a serious gap in a potential source of education on TSE. This has also been identified in other studies [33, 37, 53, 54]. One reason for this could be that TC awareness training is not promoted during Medical, Nursing, or health visitors training who all can play a key role in this regard [53, 55-57]. Brenner et al. [54] also reported that fewer than half of the pediatric residents educate patients on TSE since they believe it can cause excess anxiety. Increased TSE awareness training for physicians, nurses, GPs and public health officers has been shown to decrease delay in the diagnosis of TC and improve disease-free survival $[17,52,56,58]$. This is important because physician recommendation on TSE practice has been found to have striking success, with men who reported a physician recommendation for TSE having at least six times higher odds of performing regular TSE compared with those who reported no such recommendation [59].

The current study found that younger people (16-45 years old), and those with higher level of education and income have better knowledge of TSE. The fact that younger people within the risk age of 16-45 years old have better knowledge of how to carry out a TSE is encouraging. However, this still indicates that a substantial number of respondents within the risk age bracket are still uninformed about TSE. Similar findings in relation to age, education and income have been reported before $[17,23,48,60,61]$.

Finally, it was revealed that almost all of the respondents deemed the need for public information on TC and TSE as important. Other studies also found such high interest of respondents in accessing information and to perform TSE on a regular basis [14, 22, 24, 62]. These findings suggest that males within the risk age bracket may be open to receiving information and at least contemplate performing TSE regularly. Consequently, a campaign or educational interventions targeted at this age group may deliver positive results.

Existing controversy about the effectiveness of TSE awareness programs needs to be mentioned [63-65] although most studies have exhibited positive changes $[23,29,50,59,66]$. Promotion of TSE and public education should remain important initiatives $[45,67,68]$.

With reference to the type of ideal approaches for educational campaigns, the majority of participants in the current study suggested either a media or social media campaign. The finding related to social media is congruent with previous research $[34,48,56]$. Online education can include slide shows as available at Teens Health [69]. Individualized, tailored messages rather than group sessions have been suggested [22]. Educational brochures have been shown to lead to more positive beliefs about practical and health consequences and more positive TSE attitude and intention [26]. Cox et al.'s [70] multimedia approach to TSE training and reminding system, cuing and active modeling can present a comprehensive approach to increasing TSE regular performance among at-risk males. Mechanisms to remind males to perform TSE may potentially produce positive, sustainable health behavior choices [22].

Healthcare professionals are in an excellent position to deliver education interventions. Young men attending healthcare institutions can be given health education on TSE, perhaps accompanied by a patient leaflet. Such teaching could be incorporated into routine outpatient and inpatient interactions with high risk clients [37, 51]. In USA, males beginning at the age of 15 years are ideally provided with the knowledge to practice TSE by physicians or nurses $[51,60,71]$. Cancer registries and support groups in the United Kingdom also recommend that young men should be provided with information on basic awareness of TC and when to seek medical advice [48, 51].

Reference has likewise been made to the importance of raising awareness of both TC and TSE screening using early educational interactive sessions as a subject integrated within school subjects for boys and young men who are at highest risk [23, 35, 60, 72]. Teachers in schools

Page $7 / 15$ 
could organize seminars and conferences to inform students on the importance and practice of TSE [72]. Policy makers should consider the introduction of TSE education sessions in secondary school curricula $[51,73]$. Screening clinics at sports clubs and gymnasiums can also offer an opportunity to increase awareness of TC and TSE [74].

\section{Implications For Practice}

The results from the current study have a number of implications and recommendations for public health practice:

1. Creating effective National Public Awareness Campaigns, interactive social media and internet tools to educate young people who are most at risk.

2. Develop audiovisuals and pamphlets as supportive materials.

3. More training for healthcare professionals, including physicians, GPs and nurses to realize their important role in educating young people on TC and to encourage performance of TSE.

4. Developing TC and TSE awareness educational programs as part of School Health curricula that includes health belief scale assessment to do TSE following information provision. This could be done by trained school nurses, teachers or physical education instructors.

5 . Fitness centers and gyms could be other potential educational centres.

6. Pre-post testing of all educational campaigns initiatives implemented should be a routine procedure to ensure that the audit cycle process is closed.

7. It is recommended that future studies include studies to identify GPs and health centers physicians' awareness of how to do TSE and if they are educating young persons.

8. Studies specifically targeting populations for at-risk age bracket of $16-45$ years will provide a more focused target population.

\section{Conclusion}

This study had a substantial number of male respondents $(n=400)$ stratified according to the districts of Malta and to all age brackets. The study assessed the level of knowledge and awareness of TC and TSE as well as the practice of TSE in the male population of Malta. The results are consistent with previous evidence that males generally lack information about TC and TSE. Knowledge of TSE is associated with younger age, higher level of education and high income. However, it is not affected by the district of residence of the respondent. The study found a positive association between knowledge of TSE and practice of TSE. The majority of respondents were willing to learn how to perform TSE. Participants were supportive of an education campaign and the study suggests that there is a need for a National Awareness Campaign within the Maltese islands to raise awareness regarding TC and TSE. The findings of this study are being utilized by the Ministry for Health of Malta and the Marigold Foundation to launch National Public Campaigns to raise awareness about TC and TSE.

\section{Abbreviations}

GP

General practitioner

HCPs

Health Care Professionals

TC

Testicular Cancer

TSE

Testicular self-examination

WHO

World Health Organization

\section{Declarations}

Ethics approval and consent to participate: Ethics approval was obtained via an application to the local Ethics Committee (01/2019). All participants gave verbal informed consent before participating in the study. The Ethics Committee approved the attainment of verbal consent based on the facilitation of comprehension and the reduction of the burden entailed in a written consent form.

Consent for publication: Not applicable

Availability of data and materials: Data supporting the conclusions of this study are included within the manuscript. The raw datasets analysed during the current study are available from the corresponding author on reasonable request. 
Competing interests: The authors declare that they have no competing interests regarding the publication of this paper.

Funding: The survey was funded by the Marigold Foundation (NGO).

Authors' contributions: VM conceived the study together with the Marigold Foundation. VM supervised all aspects of its conduction. DM and RA wrote the manuscript. VM and DM assisted with data analysis and interpretation of data and revised the manuscript. VM and DM assisted with the study design. DM and GH critically reviewed and revised the manuscript. All authors helped to conceptualise ideas, interpret findings and review drafts of the manuscript. DM and VM read and approved the final manuscript.

Acknowledgements: The authors would like to forward their gratitude to the Marigold Foundation for funding and the Cancer Care Pathways Directorate (Malta) for its contribution towards data collection. This study was developed as part of the activities of the Testicular Cancer Campaign (2019) in Malta.

\section{Authors' information (optional)}

DM: BSc (Hons), MSc, PhD

VM: BSc (Hons), MSc, PhD

RA: BSc (Hons), MSc

EF: Student at the University of Malta

GH: BA (Hons), MSc, PhD, Associate Professor

\section{References}

1. Daley MC. College men's knowledge, attitudes, and beliefs about testicular cancer. Am J Mens Health. 2007;1:173-82.

2. Gurney JK, Stanley J, McGlynn K, Richiardi L, Shaw C, Edwards R, et al. Testicular Cancer in New Zealand (TCNZ) study: protocol for a national case-control study. BMJ Open. 2018;8:e025212.

3. Shabbir M, Morgan RJ. Testicular cancer. JRSH. 2004;124:217-8.

4. Huyghe E, Plante P, Thonneau PF. Testicular cancer variations in time and space in Europe. Eur Urol. 2007;51:621-8.

5. Le Cornet C, Lortet-Tieulent J, Forman D, Béranger R, Flechon A, Fervers B, et al. Testicular cancer incidence to rise by $25 \%$ by 2025 in Europe? Model based predictions in 40 countries using population-based registry data. Eur J Cancer. 2014;50:831-9.

6. Garner MJ, Turner MC, Ghadirian P, Krewski D. Epidemiology of testicular cancer: an overview. Int J Cancer. 2005;116:331-9.

7. McCullagh J, Lewis G. Testicular cancer: epidemiology, assessment and management. Nurs Stand. 2005a;19:45-53.

8. Shanmugalingam T, Soultati A, Chowdhury S, Rudman S, Van Hemelrijck M. Global incidence and outcome of testicular cancer. Clin Epidemiol. 2013;5:417-27.

9. Richardson LC, Neri JA, Tai E, Jeffrey D, Glenn MPA. Testicular cancer: A narrative review of the role of socioeconomic position from risk to survivorship. Urologic Oncology: Seminars and Original Investigations. Urol Oncol. 2012;30:95-101.

10. Znaor A, Lortet-Tieulent J, Jemal A, Bray F. International variations and trends in testicular cancer incidence and mortality. Eur Urol. 2014;65:1095-106.

11. Department for Health Information and Research. Testicular Cancer in Malta. Department for Health Information and Research. 2020. http://ww.sahha.gov.mt/pages.aspx?page=45 Accessed 20 April 2020.

12. Torpy JM, Lynm C, Glass RM. Testicular Cancer. JAMA. 2008;299:718.

13. Friman PC, Finney JW. Health Education for Testicular Cancer. Health Educ Behav. 1990;17:443-53.

14. Evans REC, Steptoe A, Wardle J. Testicular self-examination: change in rates of practice in European university students, from 13 Countries, over a 10-year period. J Mens Health. 2006;3:368-72.

15. Canadian Cancer Society. Survival statistics for testicular cancer. Canadian Cancer Society. 2020 https://www.cancer.ca/en/cancerinformation/cancer-type/testicular/prognosis-and-survival/survival-statistics/?region=on Accessed 30 Jul 2020.

16. Cancer Research UK. Testicular Cancer. 2017. https://www.cancerresearchuk.org/about-cancer/testicular-cancer Accessed 30 Jul 2020.

17. Öztürk C, Fleer J, Hoekstra HJ, Hoekstra-Weebers JHEM. Delay in Diagnosis of Testicular Cancer: A Need for Awareness Programs. PLoS ONE. 2015;10:e0141244.

18. Bosl GJ, Goldman A, Lange PH, Vogelzang NJ, Fraley EE, Levitt SH, Kennedy BJ. Impact of delay in diagnosis on clinical stage of testicular cancer. Lancet. 1981;318:970-3. 
19. Macleod U, Mitchell ED, Burgess C, Macdonald S, Ramirez AJ. Risk factors for delayed presentation and referral of symptomatic cancer: evidence for common cancers. Br J Cancer. 2009;101:92-101.

20. De Visser RO, Smith JA, McDonnell EJ. That's not masculine': masculine capital and health-related behaviour. J Health Psychol. 2009;14:1047-58.

21. Nooijer de J, Lechner L, Vries de H. Help-seeking behaviour for cancer symptoms: perceptions of patients and general practitioners. Psychooncology. 2001;10:469-78.

22. Rovito MJ, Gordon TF. Perceptions of Testicular Cancer and Testicular Self-Examination Among College Men: A Report on Intention, Vulnerability, and Promotional Material Preferences. AJMH. 2001;56:500-7.

23. Akar ŞZ, Bebiş H. Evaluation of the effectiveness of testicular cancer and testicular self-examination training for patient care personnel: Intervention study. Health Educ Res. 2014;29:966-76.

24. Moore RA. Topping A. Young men's knowledge of testicular cancer and testicular self-examination: A lost opportunity? Eur J Cancer Care. 2001; 8: 137-42.

25. American Cancer Society. Can Testicular Cancer Be Found Early?. 2020b. https://www.cancer.org/cancer/testicular-cancer/detectiondiagnosis-staging/detection.html Accessed 20 Jul 2020.

26. Steffen VJ. Men's Motivation to Perform the Testicle Self-Exam: Effects of Prior Knowledge and an Educational Brochure. JASP. 2006;20:681-702.

27. Wood RY, Duffy ME. Video breast health kits: testing a cancer education innovation in older high-risk populations. J Cancer Educ. 2004;19:98-104.

28. Folkins A, Sadler GR, Ko C, Branz P, Marsh ,S, Bovee M. Improving the Deaf community's access to prostate and testicular cancer information: a survey study. BMC Public Health. 2005;5:63-72.

29. McCullagh J, Lewis G, Warlow C. Promoting awareness and practice of testicular self-examination. Nurs Stand. 2005b;19:41-9.

30. Kuzgunbay B, Yaycioglu O, Soyupak B, Kayis AA, Ayan S, Yavascaoglu CC, Beduk Y. Public awareness of testicular cancer and selfexamination in Turkey: a multicenter study of Turkish Urooncology Society. Urol Oncol. 2013;31:386-91.

31. Wanzer MB, Foster SC, Servoss T, LaBelle S. Educating young men about testicular cancer: Support for a comprehensive testicular cancer campaign. J Health Commun. 2014;19:303-20.

32. Roy RK, Casson K. Attitudes Toward Testicular Cancer and Self-Examination Among Northern Irish Males. Am J Mens Health. 2017;11:253-61.

33. Goldenring JM, Purtell E. Knowledge of Testicular Cancer Risk and Need for Self-Examination in College Students: A Call for Equal Time for Men in Teaching of Early Cancer Detection Techniques. Pediatrics. 1984;74:1093-6.

34. Saab MM, Landers M, Hegarty J. Testicular cancer awareness and screening practices: A systematic review. Oncol Nurs Forum. 2016;43:E8-23.

35. Rudberg L, Nilsson S, Wikblad K, Carlsson M. Testicular cancer and testicular self-examination: knowledge and attitudes of adolescent Swedish men. Cancer Nurs. 2005;28:256-62.

36. Rovito MJ, Cavayero C, Leone JE. Interventions Promoting Testicular Self-Examination (TSE) Performance: A Systematic Review. AJMH. 2014;9:506-18.

37. Ugboma HAA, Aburoma HLS. Public awareness of testicular cancer and testicular self-examination in academic environments: a lost opportunity. Clinics. 2011;66:1125-8.

38. Göçgeldi E, Koçak N. Evaluation of the education given to the young adult males about testicular self-examination. Gulhane Med J. 2010;52:270-5.

39. Jackson SL. Research Methods: A Modular Approach. 2nd Ed. Wadsworth/Cengage Learning, 2011.

40. Lavrakas P. Telephone surveys. In Marsden PV, Wright JD, editors. Handbook of Survey Research. 2nd Edition. UK: Emerald Group Publishing. 2010. p. 471-498.

41. Ryan J, Lopian L, Le B, Edney S, Van Kessel G, Plotnikoff R, et al. It's not raining men: a mixed-methods study investigating methods of improving male recruitment to health behaviour research. BMC Public Health. 2019;19:814.

42. Citro C. Legal and human subjects considerations in surveys. In Marsden PV, Wright JD, editors. Handbook of Survey Research. 2nd Edition. UK: Emerald Group Publishing. 2010. p. 59-82.

43. Hersch J, Barratt A, Jansen J, Houssami N, Irwig L, Jacklyn G, et al. The effect of information about overdetection of breast cancer on women's decision-making about mammography screening: study protocol for a randomised controlled trial. BMJ Open. 2014;4:e004990.

44. National Statistics Office. Population Statistics (Revisions). 2012-2016. 2018. https://nso.gov.mt/en/News_Releases/View_by_Unit/Unit_C5/Population_and_Migration_Statistics/Documents/2018/News2018_022.pdf

Page 10/15 
Accessed 07 May 2020.

45. Carlin PJ. Testicular self-examination: a public awareness program. Public Health Rep. 1986;101:98-102.

46. Agorye IJ, Beatrice O, Grace-Jane EA. Awareness and Practice of Testicular Self Examination among Male Medical Students of University Of Nigeria Enugu Campus South-East Nigeria. JNHS. 2016;3:19-24.

47. Albers P, Albrecht W, Algaba F, Bokemeyer C, Cohn-Cedermark G, Fizazi K, et al. Guidelines on testicular cancer: 2015 update. Eur Urol. 2015;68:1054-68.

48. Garner ID. A Q-Methodological Study of Male Attitudes Towards Testicular Cancer and Testicular Self-Examination. Inquiries Journal/Student Pulse. 2011;3:11.

49. Ugurlu Z, Akkuzu G, Karahan A, Beder A. Testicular Cancer Awareness and Testicular Self-Examination among University Students. Asian Pacific J Cancer Prev. 2011;12:695-8.

50. Muliira KJ, Nalwanga BP, Muliira SR, Nankinga Z. Knowledge, perceived risk, and barriers to testicular self-examination among male university students in Uganda. J Mens Health. 2012;9:36-44.

51. Atuhaire C, Byamukama A, Yumumkah Cumber RY, Nambile Cumber S. Knowledge and practice of testicular self-examination among secondary students at Ntare School in Mbarara District, South western Uganda. Pan Afr Med J. 2019;33:85.

52. Zeleke S, Zeleke A, Kefale D. Knowledge, attitude and practice towards testicular self-examination among regular undergraduate nonhealth sciences university students, Debre Tabor, Amhara Regional State, North West Ethiopia. J Cancer Prev Curr Res. 2019;10:35-41.

53. Sayger SA, Fortenberry JD, Beckman RJ. Practice patterns of teaching testicular self-examination to adolescent patients. J Adolesc Health Care. 1988;9:441-2.

54. Brenner JS, Hergenroeder AC, Kozinetz CA, Kelder SH. Teaching Testicular Self-Examination: Education and Practices in Pediatric. Residents Pediatrics. 2003;111:e239-44.

55. Pettersson A, Richiardi L, Nordenskjold A, Kaijser M, Akre O. Age at surgery for undescended testis and risk of testicular cancer. NEJM. 2007;356: 1835-1841.

56. Ustundag H. Assessment of the Testicular Self-Examination Knowledge and Health Belief Model of Health Sciences Students. International Journal of Caring Sciences. 2019;12:972-8.

57. Singer AJ, Tichler T, Orvieto R, Finestone A, Moskovitz M. Testicular carcinoma: a study of knowledge, awareness, and practice of testicular self-examination in male soldiers and military physicians. Mil Med. 1993;158:640-3.

58. Nwozichi CU. Effect of video-based teaching module on knowledge about testicular cancer and testicular self-examination among male undergraduate students. AMHS. 2019;3:215-26.

59. Vadaparampil ST, Moser RP, Loud J, Greene MH, Korde L. Factors associated with testicular self-examination among unaffected men from multiple-case testicular cancer families. Hered Cancer Clin Pract. 2009;7:11.

60. Hiteford A, Wordley J. Raising awareness and detection of testicular cancer in young men. Nurs Times. 2003;9:34-6.

61. Pour HA, Kunter D, Norouzzadeh R, Heidari MR. The Effect of Testicular Self-Examination Education on Knowledge, Performance, and Health Beliefs of Turkish Men. J Canc Educ. 2016;33:398-403.

62. Brewer G, Roy M, Watters J. Testicular self-examination in an adult community sample. Am J Mens Health. 2011;5:57-64.

63. Lin K, Sharangpani R. Screening for testicular cancer: an evidence review for the U.S. Preventive Services Task Force. Ann Intern Med. 2010;153:396-9.

64. USPSTF. Screening for testicular cancer: U.S. Preventive Services Task Force reaffirmation recommendation statement. Ann Intern Med. 2011;154:483-6.

65. Hopcroft K. Routine testicular self-examination: It's time to stop. Br Med J. 2012;344:e2120.

66. De Souza W. dos Reis PE, Gomes IP. Campos de Carvalho E. Prevention strategies for testicular and penile cancer: an integrative review. Rev Esc Enferm USP. 2011; 45: 277 - 82..

67. Khadra A, Oakeshott P. Pilot study of testicular cancer awareness and testicular self-examination in men attending two South London general practices. Fam Pract. 2002;19:294-6.

68. McGuinness LA, Obeidat S, Hickerton B, Long R. Has increasing public health awareness influenced the size of testicular tumours among adult populations over the last 40 years? AJPH. 2017;39:1.

69. Teens Health. How to Do a Testicular Self-Exam (Slideshow). 2017. https://kidshealth.org/en/teens/tse.html Accessed 30 Jul 2020.

70. Cox C, McLaughlin R, Rai S, Steen B, Hudson M. Adolescent survivors: A secondary analysis of a clinical trial targeting behavior change. Pediatr Blood Cancer. 2005;45:144-54.

71. Wilson J, Adeline P, Bungaroo D, Khadra A, White S, Bradley E, et al. Promoting Testicular Self-Examination and Awareness Amongst Young Men with Intellectual Disabilities: A Parallel Intervention Randomized Study. J Dev Disabil. 2018;23:57-70.

Page $11 / 15$ 
72. Kyle RG, Forbat L, Rauchhaus P, Hubbart G. Increased cancer awareness among British adolescents after a school-based educational intervention: a controlled before-and-after study with 6-month follow-up. BMC Public Health. 2013;13:190.

73. PSHE Association. Your Privates school pack - Orchid lesson plans. 2020. https://www.pshe-association.org.uk/curriculum-andresources/resources/your-privates-school-pack-orchid-lesson-plans Accessed 20 Jul 2020.

74. Hall RH. Promoting men's health. AFP. 2003;32:401-7.

\section{Figures}

\section{Do you know how to do a self-examination to check the testicles? (Age)}

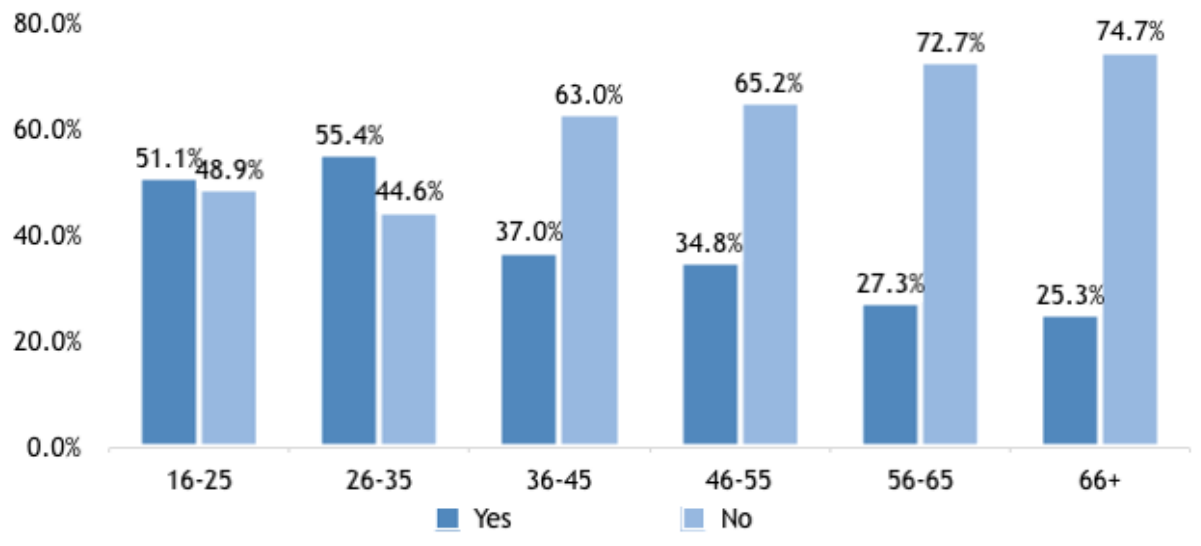

Figure 1

Knowledge of TSE per age group

Do you know how to do a self-examination to check the testicles? (Age)

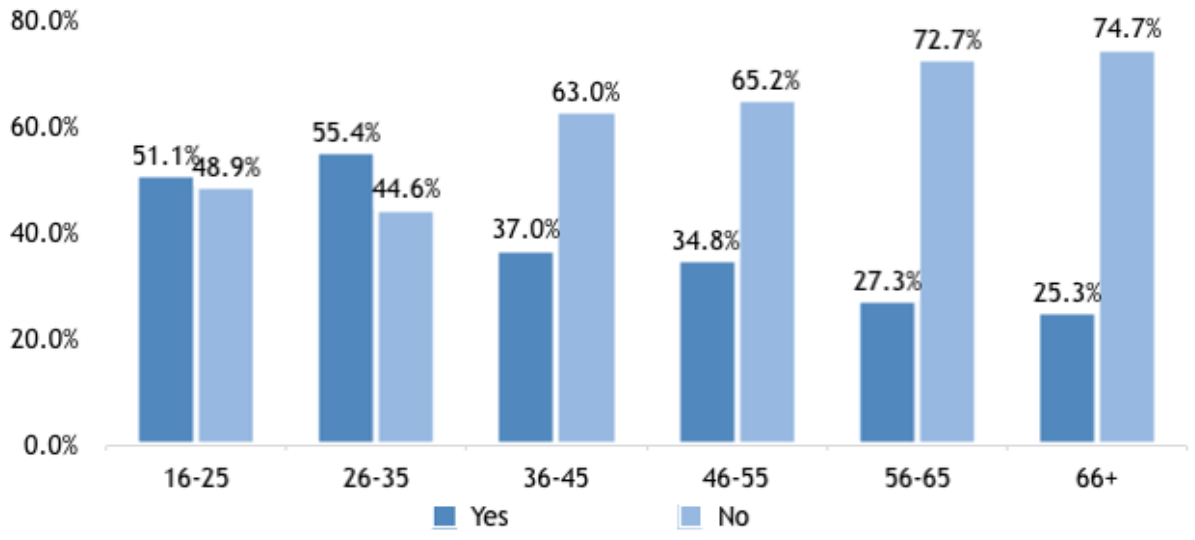

Figure 1

Knowledge of TSE per age group 
Do you know how to do a self-examination to check the testicles? (Education)

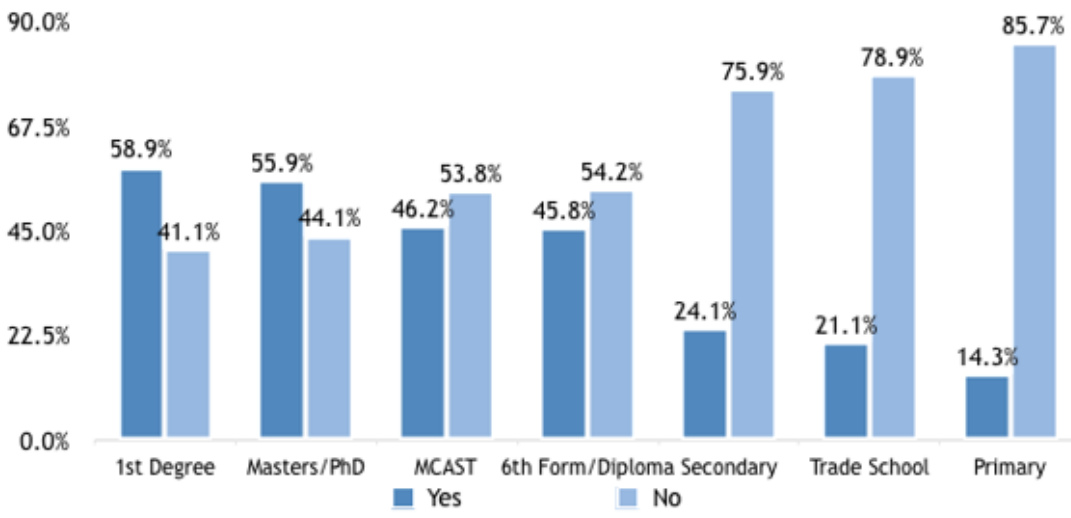

Figure 2

Knowledge of TSE and educational level

Do you know how to do a self-examination to check the testicles? (Education)

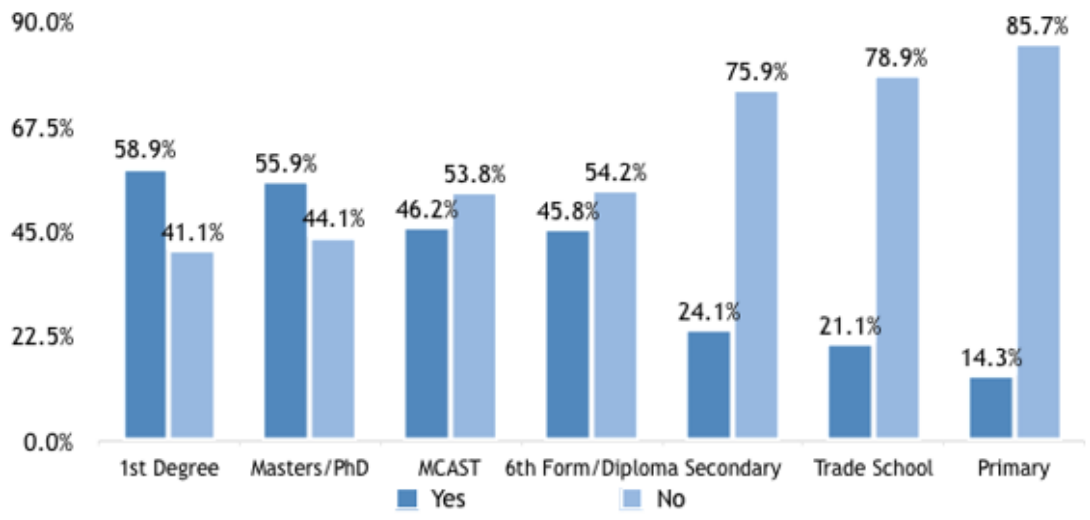

Figure 2

Knowledge of TSE and educational level

Do you know how to do a self-examination to check the testicles? (Status)

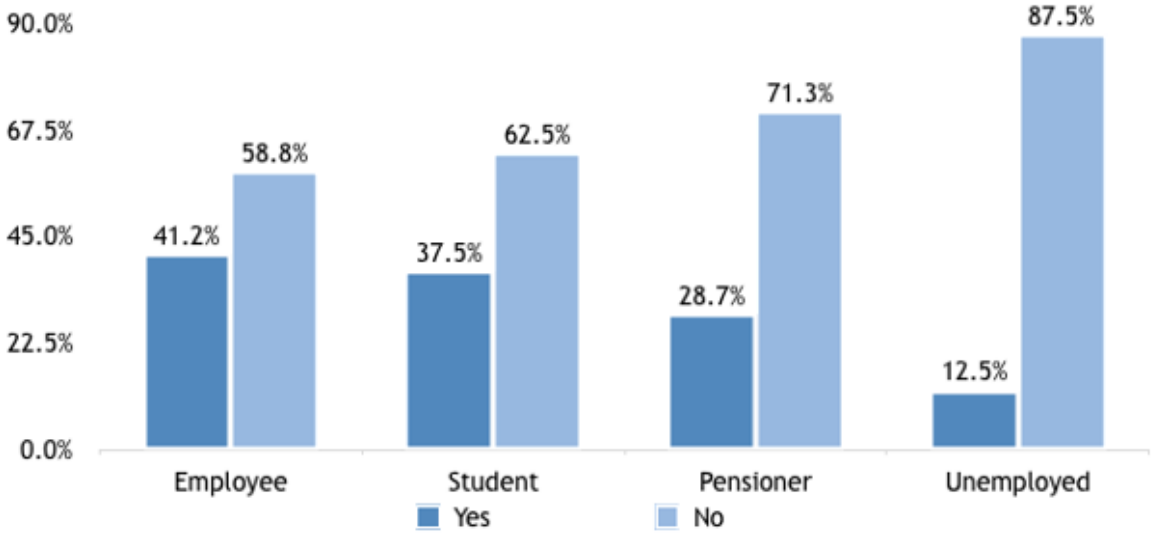

Figure 3

Knowledge of TSE and employment status 
Do you know how to do a self-examination to check the testicles? (Status)

$90.0 \%$

$87.5 \%$

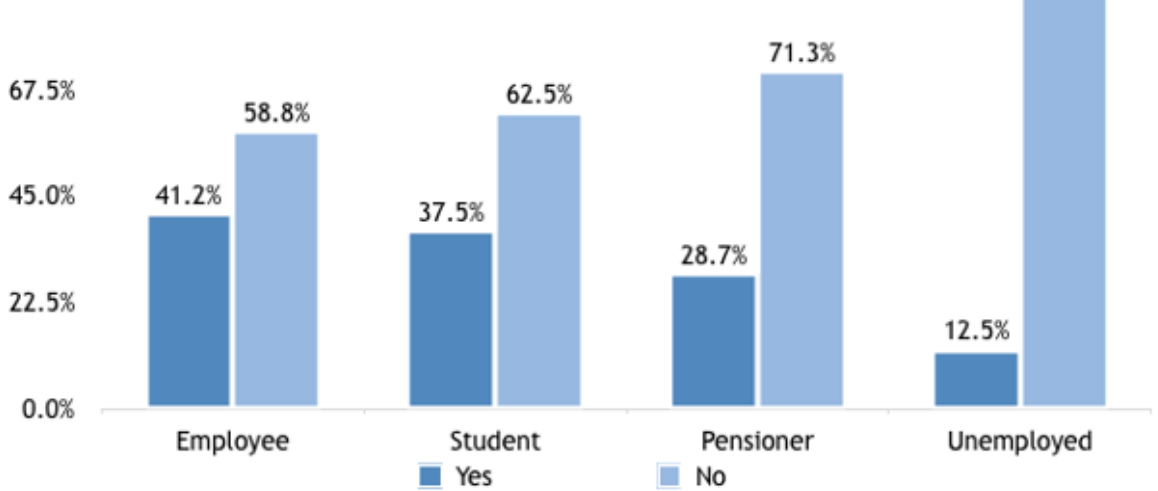

Figure 3

Knowledge of TSE and employment status

Do you know how to do a self-examination to check the testicles? (Income tax bracket)

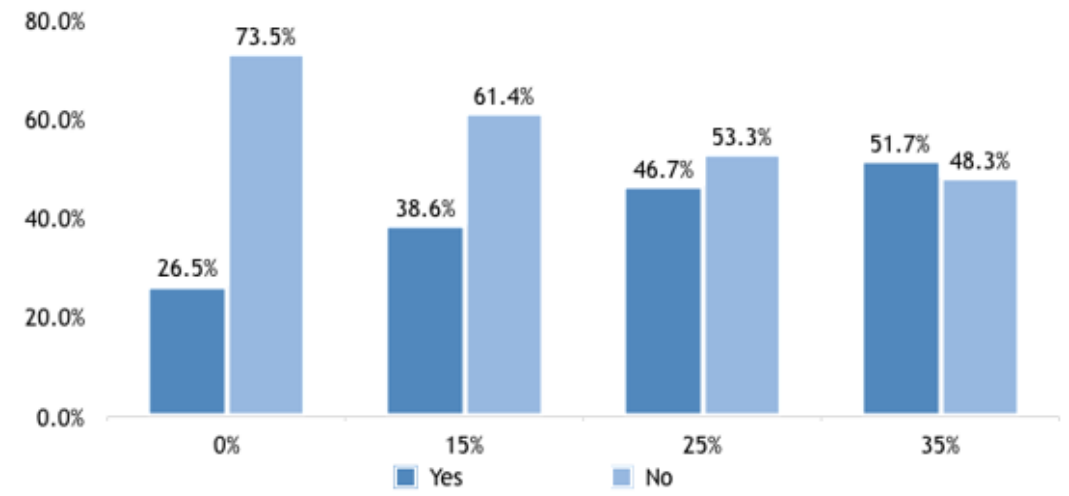

Figure 4

Knowledge of TSE and level of income

Do you know how to do a self-examination to check the testicles? (Income tax bracket)

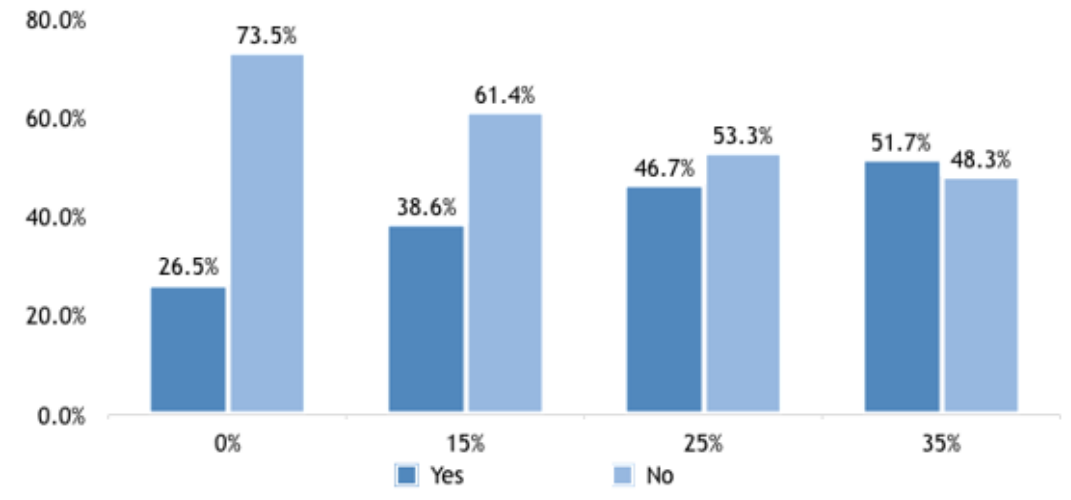

Figure 4

Knowledge of TSE and level of income 


\section{Supplementary Files}

This is a list of supplementary files associated with this preprint. Click to download.

- Testicularcancerquestionnaire.docx

- Testicularcancerquestionnaire.docx 